\title{
Generalized Feedforward Control of Single-Phase PWM Rectifiers Using Disturbance Observers
}

\author{
Rajesh Ghosh and G. Narayanan, Member, IEEE
}

\begin{abstract}
This paper presents a generalized feedforward control scheme for a single-phase boost rectifier, operating with indirect current control, to improve the dynamic response of its output voltage against line and load disturbances, as well as for changes in the reference voltage. Digital implementation of the control method is discussed. A small-signal model of the converter system is presented. The stability of the current loop at light loads is studied. A method is presented to estimate the input voltage and the load current without having to actually measure these quantities for the purpose of feedforward control. Simulation and experimental results are presented.
\end{abstract}

Index Terms-AC-DC power conversion, boost rectifier, current control, digital control, feedforward systems, observers.

\section{INTRODUCTION}

$\mathbf{S}$ INGLE-PHASE pulsewidth-modulation rectifiers [1]-[3] are increasingly used in power-factor-correction applications to comply with necessary harmonic standards [4]. Normally, low input current distortion and high input power factor are achieved by employing a high-bandwidth current control loop and a low-bandwidth (for example, $10 \mathrm{~Hz}$ ) voltage control loop [3], [5]-[8]. The voltage loop is designed for low bandwidth to avoid input current distortion caused by the output voltage ripple. Such a rectifier system exhibits poor dynamic response against input voltage and load disturbances. The output voltage is unsteady, when there is pulsed loading [9] and/or the input voltage contains dips or swells due to frequent additions or rejections of bulk loads connected to the supply. As a result, the components of the rectifier and its downstream converter experience increased voltage and current stresses. The other adverse effects are loss of regulation, increased cost, and reduced efficiency of the downstream converter [10]-[12].

Several control techniques are reported in the literature to overcome the above problems. These can be broadly classified into three categories. The first one suggests different methods to eliminate the low-frequency ripple from the measured output voltage before it is processed by the voltage loop and, thereby, to increase the bandwidth of the voltage loop. Notch filtering, ripple compensation, dead-zone analog-to-digital converter (ADC), and comb filtering fall under this category [6]-[8],

Manuscript received March 6, 2006; revised August 30, 2006. Abstract published on the Internet January 14, 2007.

R. Ghosh is with the Power Electronics Group, Department of Electrical Engineering, Indian Institute of Science, Bangalore 560 012, India (e-mail: rajesh@ee.iisc.ernet.in).

G. Narayanan is with the Department of Electrical Engineering, Indian Institute of Science, Bangalore 560 012, India.

Color versions of one or more of the figures in this paper are available online at http://ieeexplore.ieee.org.

Digital Object Identifier 10.1109/TIE.2007.892103
[10]-[12]. Though a notch filter or a ripple compensator can eliminate the second harmonic, it cannot eliminate the fourth and higher order harmonics in the output voltage [11], [12]. As a result, the use of wide-bandwidth voltage loops in such cases results in corresponding harmonic distortions in the input current [11], [12]. The dead-zone ADC control [12] is reported to have limit cycle oscillations at light loads, whereas the implementation of the comb filter requires large memory storage [11].

The next one is the regulation band [6], [7], where the bandwidth of voltage loop is kept low at steady state to obtain a sinusoidal input current. During transients, it is increased to have a good dynamic response. The output voltage error is used to determine whether the rectifier is at steady state or in the transient condition. The input current, however, contains lowfrequency ripple during transients [6].

The last category is the feedforward control, where the dynamic response of the output voltage is improved by injecting measured disturbances as feedforward input to the system. For instance, the input voltage feedforward is used to compensate the input voltage disturbance [13]-[15]. If it is required to compensate both line and load disturbances, then the input voltage and load current feedforward scheme is employed [16]-[18]. A similar input voltage feedforward scheme is used in [3]. Instead of using load current feedforward, the dynamic response of the output voltage against load disturbances is improved by introducing an additional feedback loop parallel to the voltage controller [3].

The feedforward control reported for a dc-dc converter [16] and for an ac-dc converter [17], [18] work on the same principle. In this approach, the original voltage loop is designed for low bandwidth. Instead of depending on the slow voltage loop, the input power reference (or input current reference) to the converter system is quickly calculated and updated based on the measured input voltage, output voltage, and load current. The voltage controller only makes up for the system nonidealities and ensures steady state accuracy.

In [17], the above control is demonstrated on a singlephase boost rectifier system (two-switch and two-diode topology) with a variable-switching-frequency hysteresis controller. While implementing the above control, input voltage, input current, output voltage, and load current are measured.

This paper extends the above control concept to single-phase boost rectifier system, operating with indirect current control [19], [20] at a constant switching frequency. Although input voltage and load current are not required for indirect current control or resistance emulation method, these quantities are needed for the purpose of feedforward control to improve 


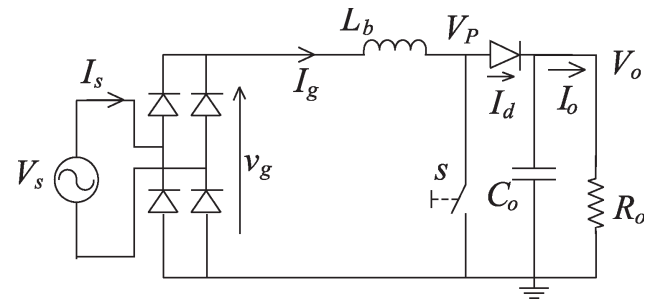

Fig. 1. Single-phase boost rectifier.

the output voltage response. Two disturbance observers are proposed to estimate these two quantities without having to measure these with sensors.

A complete analysis of the above system, including current loop instability at light load and sensitivity of the proposed estimators against parameter variations, is presented. The proposed control is implemented on a TMS320LF2407based digital platform and validated on an experimental boost rectifier prototype. The experimental results show improved dynamic response of the output voltage. These are compared with the corresponding experimental results as obtained with conventional control (without feedforward) and also with the proposed feedforward control using additional input voltage and load current sensors.

\section{INDIRECT CURRENT CONTROL}

This section briefly discusses the indirect current control [20] for boost rectifier (see Fig. 1), which is used to demonstrate the proposed feedforward control.

The average input and output voltages $v_{g}$ and $V_{o}$ of the boost converter (Fig. 1) may be related to the duty ratio $D$ of switch $S$ as in (1), where $V_{g m}$ and $\omega$ are peak input voltage and supply angular frequency, respectively. The desired switchingcycle averaged input current $I_{g}$ is shown in (2), where $R_{e}$ is the emulated resistance of the converter, and $I_{g m}$ is the amplitude of $I_{g}$ [20]. A proportional-integral (PI)-type voltage controller with output $V_{m}$ as in (3) is used to control the output voltage $V_{o}$, where $R_{s}$ is current sensing gain [20]. Equations (1)-(3) yield the discrete control law for the $n$th switching cycle as follows:

$$
\begin{aligned}
v_{g} & =(1-D) V_{o}=V_{g m} \sin (\omega t) \\
I_{g} & =v_{g} / R_{e}=I_{g m} \sin (\omega t) \\
V_{m} & =V_{o} R_{s} / R_{e} \\
D[n+1] & =1-\frac{\left(I_{g} R_{s}\right)[n]}{V_{m}[n]} .
\end{aligned}
$$

The $n$th switching-cycle output of the voltage controller is shown in (5), where $e_{V}[n]=K_{V}\left(V_{o}^{*}[n]-V_{o}[n]\right)$ is the output voltage error, $K_{1}$ and $K_{2}$ are constants, $V_{o}^{*}[n]$ is the reference output voltage, and $K_{V}$ is the output voltage sensor gain. The equivalent analog representation of (5) is shown in (6) as follows:

$$
\begin{aligned}
& V_{m}[n]=V_{m}[n-1]+K_{1} e_{V}[n]-K_{2} e_{V}[n-1] \\
& V_{m}(t)=K_{\mathrm{PI}} K_{V} e_{V}(t)+\frac{K_{\mathrm{PI}} K_{V}}{T_{\mathrm{PI}}} \int e_{V}(t) d t
\end{aligned}
$$

where $K_{\mathrm{PI}}$ and $T_{\mathrm{PI}}$ are the controller parameters. The desired constants $K_{1}$ and $K_{2}$ may be related with $K_{\mathrm{PI}}$ and $T_{\mathrm{PI}}$ [21].

The corner frequency of the voltage controller is placed at $7.5 \mathrm{~Hz}$. The corresponding parameters, $K_{\mathrm{PI}}=1$ and $T_{\mathrm{PI}}=$ $20 \mathrm{~ms}$, ensure that the input current total harmonic distortion (THD) factor, caused by the output voltage ripple, is within $1 \%$. A detailed method of selecting $K_{\mathrm{PI}}$ and $T_{\mathrm{PI}}$ is discussed in [22].

\section{Proposed FeEdForward CONTROL}

Feedforward control is an effective means of attenuating the effects of various disturbances acting on the system by adding a feedforward signal, derived from the disturbance inputs, to the output of the feedback controller. For instance, dutyratio feedforward improves input current displacement factor [23], and reference current feedforward reduces input current distortion [24]. The input voltage and load current feedforward control improves the system dynamic response against line and load disturbances [16], [17].

This section presents a feedforward control scheme for the single-phase boost rectifier system, operating with indirect current control [20], to make the converter system insensitive to line and load disturbances besides improving the dynamic response to changes in reference voltage.

\section{A. Derivation of the Feedforward Term}

It is seen in (3) that, in addition to input voltage, the steady state input power $P_{\text {in }}$ to the converter can be controlled through $V_{m}$. The steady state output power $P_{o}$ is, however, decided by the load current $I_{o}$. The voltage controller adjusts $V_{m}$ in a way to maintain balance between $P_{\text {in }}$ and $P_{o}$ by forcing the voltage error $e_{V}$ to be zero. Using the input-output power balance (7), the steady state value of $V_{m}$ (3) can be expressed in terms of $V_{g m}, V_{o}^{*}$, and $I_{o}$ as follows:

$$
\begin{aligned}
P_{o} & =V_{o}^{*} I_{o}=V_{g m} I_{g m} / 2=V_{g m}^{2} /\left(2 R_{e}\right) \\
V_{m, s s} & =2 I_{o} R_{s}\left(V_{o}^{*} / V_{g m}\right)^{2} .
\end{aligned}
$$

The input-output power balance is disturbed during transients. The voltage controller is slow, and hence, there is a delay in restoring the balance. This causes momentary discharging or overcharging of the output capacitor $C_{o}$, which is reflected as undershoot or overshoot in $V_{o}$. The above transients could be reduced considerably, if the input power could be changed quickly in accordance with the output power to restore the balance. This requires $V_{m}$ to be changed fast.

Since the PI controller cannot be made any faster as discussed earlier, one can introduce a faster path parallel to the voltage controller to change $V_{m}$. This is a feedforward path using the right-hand side of (8). The voltage PI controller only makes up for nonidealities and measurement errors and ensures steady state accuracy.

The control parameter $V_{m}[n]$ for the $n$th switching cycle is now redefined in the following equation:

$$
\begin{aligned}
V_{m}[n] & =V_{m(V C)}[n]+V_{m(F F)}[n] \\
& =V_{m(V C)}[n]+2\left(\frac{V_{o}^{*}[n]}{V_{g m}[n]}\right)^{2} I_{o} R_{s}[n]
\end{aligned}
$$




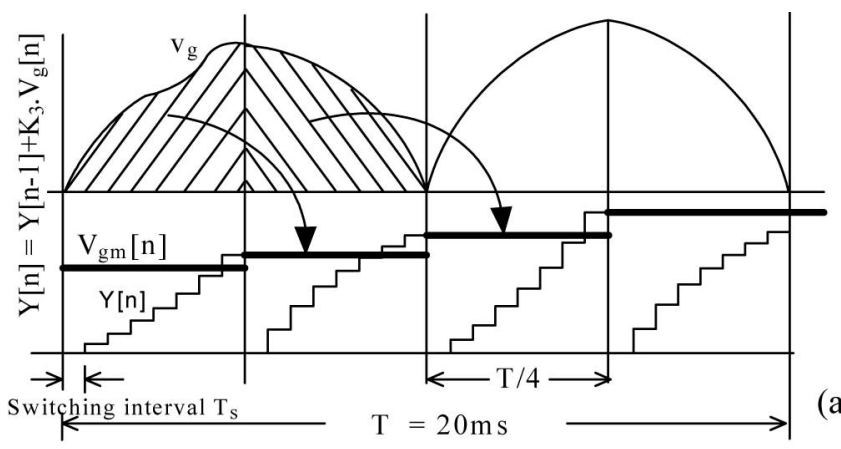

(a)

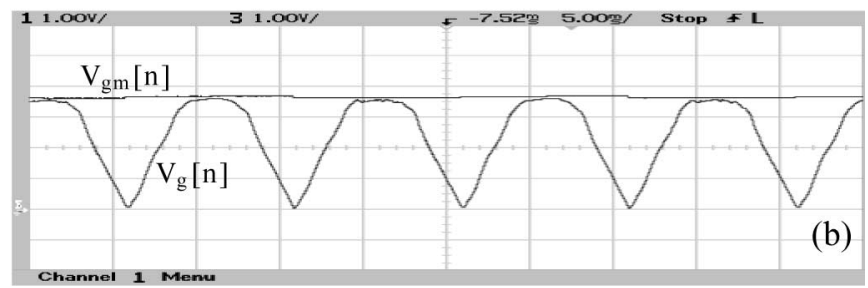

Fig. 2. Computation of peak input voltage. (a) Theoretical. (b) Experimental.

where $V_{m(V C)}[n]$ is the output of the PI controller and $V_{m(F F)}[n]$ is the feedforward term.

The feedforward term in (9) is a generalized one to compensate for disturbances in the input voltage and/or the load current, as well as for change in the voltage reference.

\section{B. Computation of the Peak Input Voltage}

The control (9) requires the peak input voltage $V_{g m}[n]$. The peak input voltage can be obtained either using a peak detector or by filtering the input voltage with a low-pass filter [3], [25].

The former method is prone to noise. Any noise in the input voltage propagates in square through $V_{m(F F)}[n]$. On the other hand, use of a low-pass filter introduces a long delay in peak (or average) voltage sensing.

In this paper, the sampled input voltage $v_{g}[n]$ is integrated over successive quarters of the line cycle as in Fig. 2(a). The zero crossings of $v_{q}[n]$ are used for the necessary synchronization. The integration constant $K_{3}$ is selected in a way to obtain $V_{g m}[n]$ from the output of the integrator at the end of every quarter line cycle before the integrator is reset. This method is better than peak sensing because the computational delay is only a quarter line cycle and the integration action attenuates the sampling noises. It is also seen that a little variation of line frequency around its nominal value has negligible effect on $V_{g m}[n]$. Fig. 2(b) shows an experimental snapshot of $V_{g m}[n]$.

\section{Proposed Digital Controller}

The block diagram of the rectifier system with the proposed control is shown in Fig. 3. The control is implemented on a TMS320LF2407-based digital platform. The measured input current and output voltage are sampled at the middle of the switch turn-off interval to avoid sampling the switching noises [26]. The input voltage and load current information required for computing $V_{m}[n]$ (9) is obtained using two estimators, which are discussed in greater detail in Section V. Fig. 4 shows the control-timing diagram.

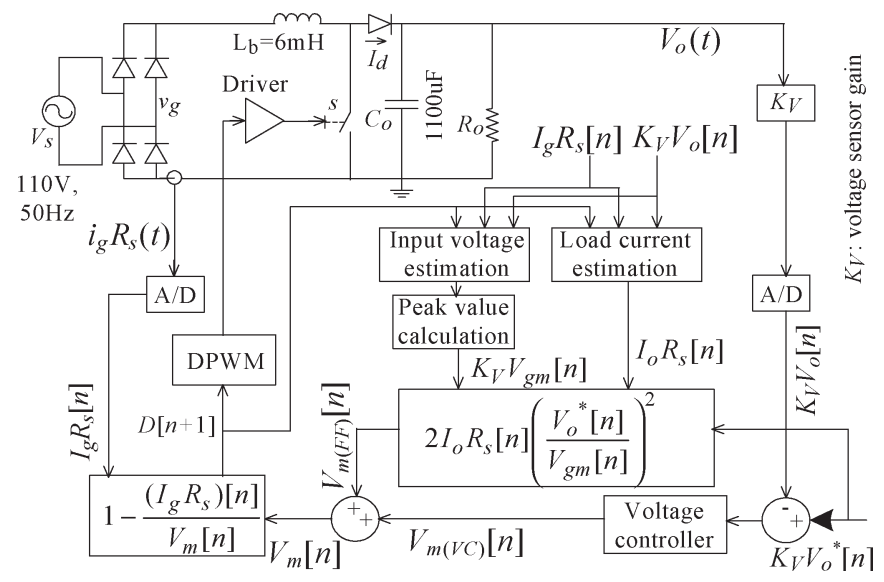

Fig. 3. Boost rectifier system with the proposed feedforward control.

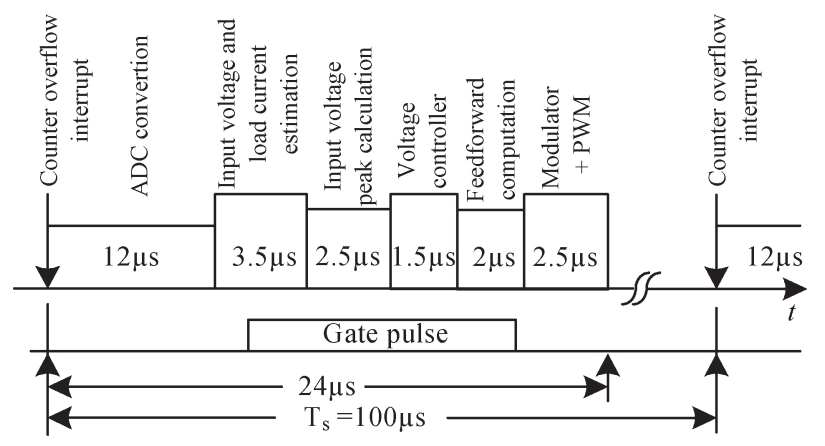

Fig. 4. Timing diagram of the control algorithm.

\section{SMALl-Signal ANALYSiS}

The averaged small-signal analysis of a single-phase rectifier system, employing the two-switch and two-diode topology, and hysteresis controller is reported in [17]. This section presents a similar small-signal analysis for the rectifier system shown in Fig. 3 with the proposed method of control.

\section{A. Small-Signal Model Without Feedforward Control}

The switching-cycle averaged model of the rectifier system (without feedforward) is obtained using (4), (10)-(12), and Fig. 3 as shown in Fig. 5, where $V_{P}^{\prime}=(1-D) V_{o}$ as given in (12), $V_{L}$ is the averaged voltage across $L_{b}$, and $I_{d}$ is the averaged diode current. Considering all the possibilities, an average delay $T_{d}=1.5 T_{s}$ is considered to represent the delay involved in digital implementation [27]. We have

$$
\begin{aligned}
V_{L} & =L_{b} \frac{d I_{g}}{d t}=v_{g}-V_{P} \\
I_{d} & =C_{o} \frac{d V_{o}}{d t}+\frac{V_{o}}{R_{o}}=(1-D) I_{g}=I_{g}^{2} R_{S} / V_{m} \\
V_{P}^{\prime} & =\left(I_{g} R_{S} / V_{m}\right) V_{o}=(1-D) V_{o} .
\end{aligned}
$$

Equations (11) and (12) are linearized in (13) and (14) as follows:

$$
\begin{aligned}
\hat{i}_{d}(s) & =2 m_{g} \hat{i}_{g}(s)-\left(m_{g}^{2} / R_{s}\right) \hat{v}_{m}(s) \\
\hat{v}_{P}^{\prime}(s) & =m_{g} \hat{v}_{o}(s)+R_{e} \hat{i}_{g}(s)-\left(m_{g} R_{e} / R_{s}\right) \hat{v}_{m}(s)
\end{aligned}
$$

where $m_{g}=M_{g} \sin \omega t$, and $M_{g}=V_{g m} / V_{o}$. 


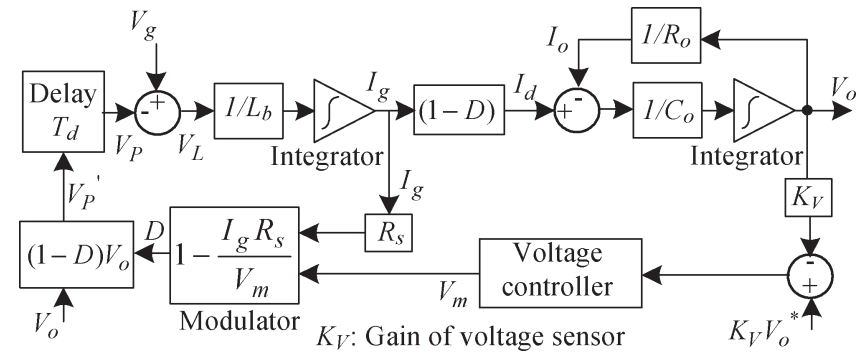

Fig. 5. Averaged model without feedforward control.

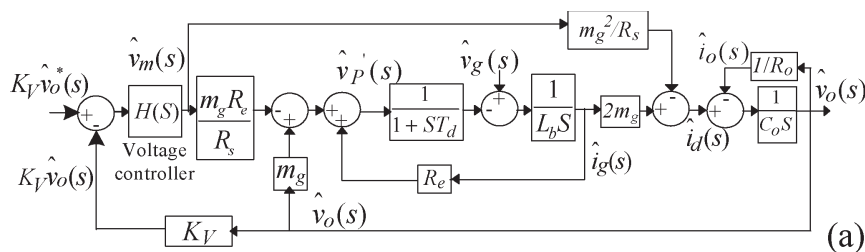

(a)

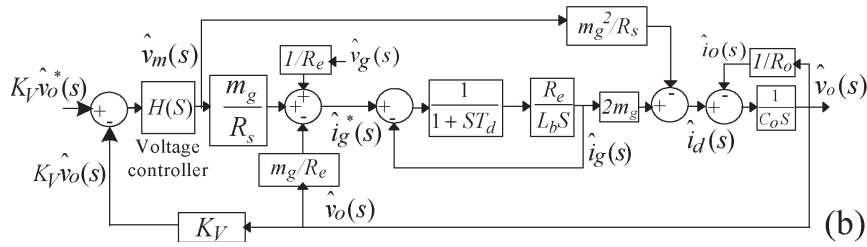

Fig. 6. (a) Small-signal model without feedforward control. (b) Its simplified model, showing the equivalent current loop.

Fig. 6(a) shows the small-signal model of the converter system as obtained using (13), (14), and Fig. 5, where the delay $T_{d}$ is represented by $e^{-s T d} \approx 1 /\left(1+s T_{d}\right)$ [28]. Fig. 6(b) shows its simplified model, where it is seen that the system has an equivalent current loop with $I_{g}^{*}$ as the reference current. The loop gain of the current loop is shown in (15). It can be seen that, if $T_{d}=0$ (i.e., in case of analog implementation), the current loop is a first-order system with time constant $T_{I}=L_{b} / R_{e}$ as in [19]. However, because of the delay $T_{d}$, the effective current loop is a second-order system. Further, it can be seen that, for a particular $L_{b}$ and $T_{d}$, the dc gain of (15) increases with a decrease in load or an increase in $R_{e}$, i.e.,

$$
G_{c}(s) H_{c}(s)=\frac{R_{e}}{s\left(1+s T_{d}\right) L_{b}} .
$$

Fig. 7 shows the bode plot of (15) for different loads (see parameters in Table I). It can be seen that the system phase margin decreases as the load is reduced. Therefore, at light load, the current loop can have instability. This agrees with the observations in [29]. In this paper, this issue is experimentally verified in Section VI.

The voltage loop is much slower than the current loop. Therefore, in order to analyze the voltage loop, the current loop dynamics and the effect of delay $T_{d}$ may be ignored. The current loop may be represented by its dc gain. With this, the plant transfer function $G_{L}(s)$ is defined in (16), whose parameters are shown in (17) as follows:

$$
G_{L}(s)=\left.\frac{K_{V} \hat{v}_{o}(s)}{\hat{v}_{m}(s)}\right|_{\hat{v}_{g}=0}=\frac{G_{V} K_{V}}{1+s T_{V}}
$$

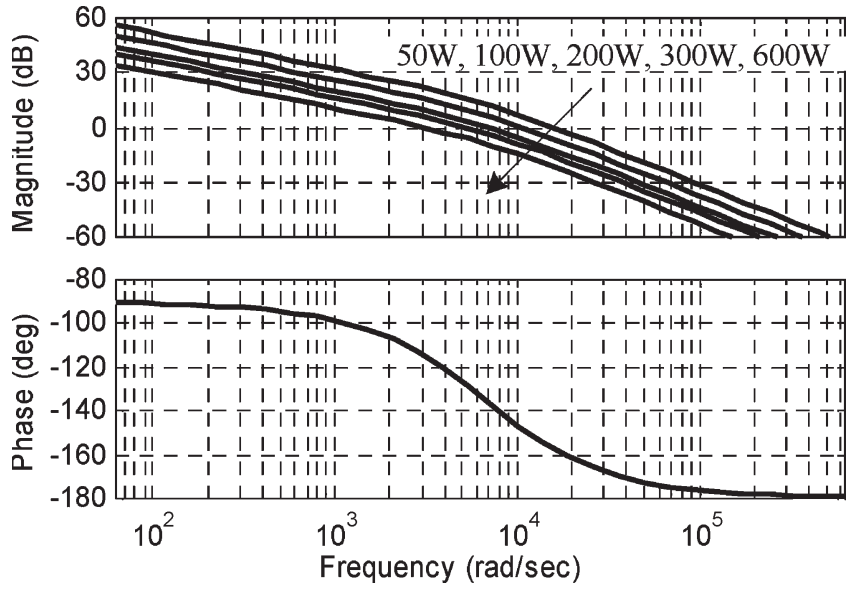

Fig. 7. Bode plot of current loop gain.

TABLE I

PARAMETERS AND COMPONENTS OF THE System

\begin{tabular}{|l|l|l|l|l|}
\hline$P_{o}$ & $600 \mathrm{~W}$ & & $L_{b}$ & $6 \mathrm{mH}$ \\
\hline$V_{g m}$ & $156 \mathrm{~V}$ & & $R_{L}$ & $0.4 \Omega$ \\
\hline$V_{o}$ & $215 \mathrm{~V}$ & & $C_{o}$ & $1100 \mu \mathrm{F}$ \\
\hline$f$ & $50 \mathrm{~Hz}$ & & $R_{c}$ & $10 \mathrm{k} \Omega$ \\
\hline$f_{s w}=1 / T_{S}$ & $10 \mathrm{kHz}$ & & $K_{v}$ & $1 / 290$ \\
\hline$V_{b}$ & $290 \mathrm{~V}$ & & $R_{S}$ & $0.1 \Omega$ \\
\hline$I_{b}$ & $10 \mathrm{~A}$ & & $S$ & $\mathrm{CM} 50 \mathrm{DY}-12 \mathrm{H}$ \\
\hline
\end{tabular}

$$
G_{V}=\frac{m_{g}^{2} R_{o} / R_{s}}{1+2 m_{g}^{2} R_{o} / R_{e}} \quad T_{V}=\frac{R_{o} C_{o}}{1+2 m_{g}^{2} R_{o} / R_{e}} .
$$

The plant $G_{L}(s)$ depends on $m_{g}^{2}$, where $m_{g}$ varies sinusoidally. This causes second harmonic ripple in $V_{o}$. However, the quantity of interest in the small-signal analysis is the mean value $V_{o}$, not the voltage ripple. Hence, $m_{g}^{2}$ in (17) may be replaced by its average value $\left(0.5 M_{g}^{2}\right)$. With this, the simulated and measured bode plots of $G_{L}(s)$ at rated operating condition are shown in Fig. 8(a) and (b), respectively. The corner frequency of $G_{L}(s)$ is around $5.5 \mathrm{~Hz}$.

The small-signal model [Fig. 6(b)] is further simplified in Fig. 9(a), where the disturbance inputs $\hat{v}_{g m}$ and $\hat{i}_{o}$ are clearly shown. The objective of the proposed feedforward control is to compensate for the above disturbances by injecting equal and opposite terms in the controller.

\section{B. Small-Signal Model With Feedforward Control}

The feedforward term $V_{m(F F)}$, as shown in (9), is linearized in (18). The linearized small-signal model of the system is shown in Fig. 9(b). It can be seen that the effects of the disturbances $\hat{v}_{g m}$ and $\hat{i}_{o}$ on the voltage loop are completely compensated by the feedforward inputs $K_{V} \hat{v}_{g m}$ and $\hat{i}_{o} R_{s}$, i.e.,

$$
\begin{array}{r}
\hat{v}_{m(F F)}(s)=\frac{2 R_{s}}{M_{g}^{2}} \hat{i}_{o}(s)+\frac{4 R_{s} K_{V}}{K_{V} R_{o} M_{g}^{2}} \hat{v}_{o}^{*}(s) \\
-\frac{2 R_{s} K_{V}}{K_{V} R_{e} M_{g}} \hat{v}_{g m}(s) .
\end{array}
$$

The compensated model is shown in Fig. 10.

The effective feedforward path, which is still present in the system (Fig. 10) is the one, which is derived from $K_{V} \hat{v}_{o}^{*}$. 


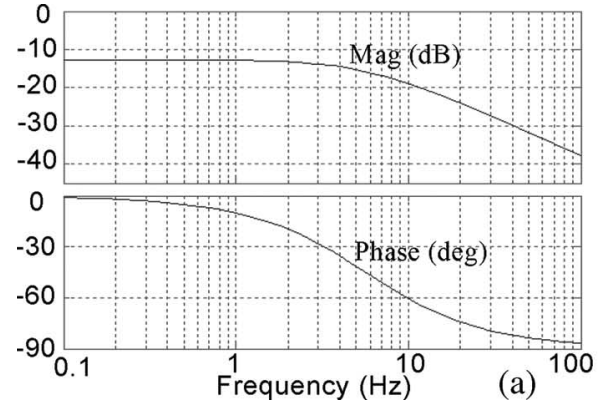

Fig. 8. Bode plot of $G_{L}(s)$. (a) Simulation. (b) Experimental.
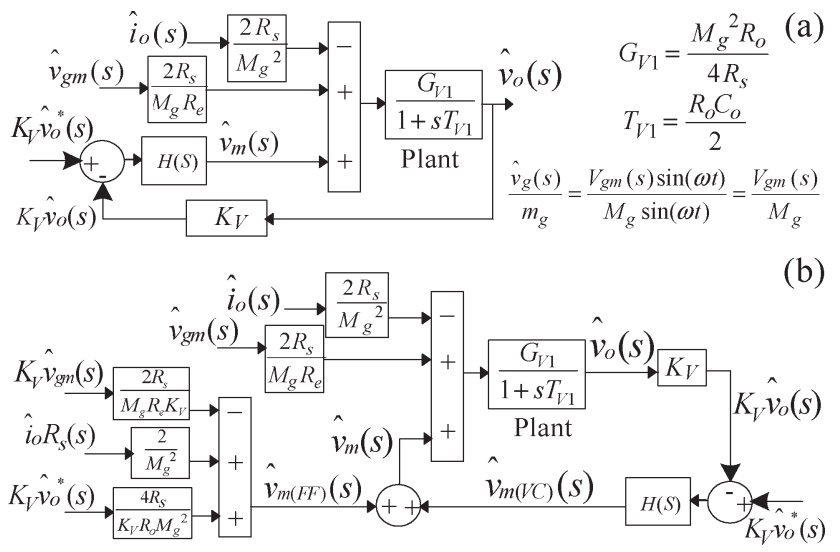

Fig. 9. Small-signal model. (a) Without feedforward control. (b) With feedforward control.

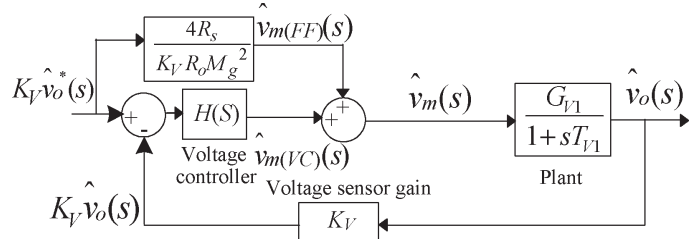

Fig. 10. Compensated small-signal model of the converter system.

In most of the applications, the reference voltage $V_{o}^{*}$ is unique and constant (i.e., $\hat{v}_{o}^{*}=0$ ). In such cases, the above path remains ineffective. However, when there is transient in $V_{o}^{*}$, this feedforward path comes in parallel with the voltage controller and increases its effective proportional gain. This helps improve the system dynamic response. However, the high proportional gain slightly increases the overshoot and/or undershoot in output voltage $V_{o}$ as discussed in Section VI.

\section{InPut Voltage AND LOAD CURRENT Estimation}

This section presents two disturbance observers to obtain the required input voltage and load current information for the proposed feedforward control. These may be used in many power electronic systems to avoid sensing the above quantities.

It should be noted that neither $v_{g}$ nor $I_{o}$ is a state of the system. The states of the system $\left(I_{g}\right.$ and $\left.V_{o}\right)$ are first estimated. The error between the estimated and the measured values of the states is used to estimate $v_{g}$ and $I_{o}$ as discussed below.
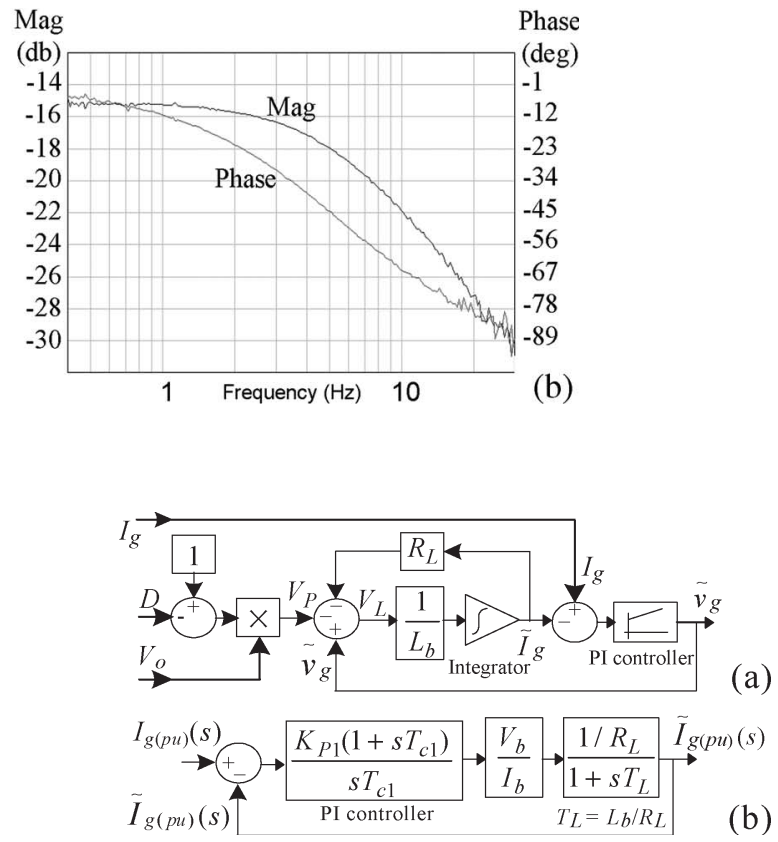

Fig. 11. (a) Input voltage estimation scheme. (b) Its per-unit equivalent frequency-domain model.

\section{A. Input Voltage Estimation}

The input voltage estimation scheme is shown in Fig. 11(a), where $R_{L}$ is the inductor resistance. The measured input current $I_{g}$ is estimated as $\tilde{I}_{g}$ using the input side model of the converter. The estimated input voltage $\tilde{v}_{g}$ is obtained by processing the input current error $\left(I_{g}-\tilde{I}_{g}\right)$ using a PI controller as shown.

Assuming $V_{o}$ to be a disturbance input, Fig. 11(b) shows the per-unit equivalent model of the above system, where $V_{b}$ and $I_{b}$ are the base voltage and base current, respectively, $I_{g(\mathrm{pu})}=$ $I_{g} / I_{b}, \tilde{I}_{g(\mathrm{pu})}=\tilde{I}_{g} / I_{b}$, and $K_{P 1}$ and $T_{c 1}$ are the parameters of the PI controller. In order to select $K_{P 1}$ and $T_{c 1}$, one can choose $T_{c 1}=T_{L}$ to cancel out the effect of pole $\left(1+s T_{L}\right)$ and use a high-valued $K_{P 1}$ to obtain a good estimation speed.

It should be noted that, unlike the actual pole voltage $\left(V_{P}\right.$ in Fig. 1), the computed pole voltage $\left[V_{P}\right.$ in (Fig. 11(a)] does not contain switching-frequency components as it is derived using $D$. Due to this reason, the estimated input current $\tilde{I}_{g}$ is smooth. However, the sampled input current $I_{g}$ contains sampling error, which is reflected in the steady state error $\left(I_{g}-\tilde{I}_{g}\right)$. It is seen that the above sampling error gets amplified when a fast PI controller is used. This causes increased harmonic distortion (at sampling frequency) in $\tilde{v}_{g}$.

Considering the above, the PI controller parameters are chosen to be $K_{P 1}=1.5$ and $T_{c 1}=0.5 \mathrm{~ms}$, which is a good tradeoff between the estimation speed and the above distortion. The $0-\mathrm{dB}$ crossover frequency and the phase margin of the loop gain are $7.5 \mathrm{kHz}$ and $75^{\circ}$, respectively.

\section{B. Load Current Estimation}

The load current estimation scheme is shown in Fig. 12(a), where $R_{c}$ is the equivalent shunt resistance of $C_{o}$. It is derived using the output side model of the converter. Here, the measured 


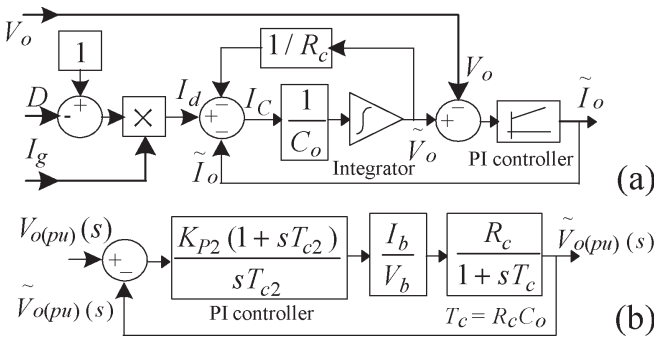

Fig. 12. (a) Load current estimation scheme. (b) Its per-unit equivalent frequency-domain model.

output voltage $V_{o}$ is estimated as $\tilde{V}_{o}$. The voltage error $\left(\tilde{V}_{o}-\right.$ $\left.V_{o}\right)$ is processed in a PI controller, whose output is used as the estimated load current $\tilde{I}_{o}$ as shown.

Considering $I_{g}$ to be a disturbance, the per-unit equivalent model of the above system is shown in Fig. 12(b), where $V_{o(\mathrm{pu})}=V_{o} / V_{b}$, and $\tilde{V}_{o(\mathrm{pu})}=\tilde{V}_{o} / V_{b}$. Similar to the input voltage estimation scheme, it is seen that a fast PI controller introduces switching-frequency harmonic distortion in the estimated load current. Considering the above, the PI controller parameters $K_{P 2}$ and $T_{c 2}$ are selected to be 2 and $10 \mathrm{~ms}$, respectively. The $0-\mathrm{dB}$ crossover frequency and the phase margin of the loop gain are $100 \mathrm{~Hz}$ and $45^{\circ}$, respectively.

\section{Performance Analysis of the Estimators}

The estimation schemes shown in Figs. 11(a) and 12(a) replicate the input and output sides of the rectifier, respectively. Further, each contains a PI controller in the loop. Therefore, in the steady state, the instantaneous errors between the actual and estimated quantities are small as long as the parameters $L_{b}, R_{L}, C_{o}$, and $R_{c}$ remain around their nominal values. However, in practice, the above parameters may vary with time, temperature, etc.

In order to study the performance of the estimators against real circuit parameter variations, sensitivity analysis is performed [28]. The objective is to see the dependence of the closed-loop transfer functions $T_{I}(s)=\tilde{I}_{g(\mathrm{pu})}(s) / I_{g(\mathrm{pu})}(s)$ and $T_{V}(s)=\tilde{V}_{o(\mathrm{pu})}(s) / V_{o(\mathrm{pu})}(s)$ on the variations in the circuit parameters. The corresponding sensitivities are defined in (19) and (20) [28], where $G_{I}$ and $G_{V}$ are the respective open-loop transfer functions, and $K_{e 1}$ and $K_{e 2}$ are defined as follows:

$$
\begin{aligned}
S_{G_{I}}^{T_{I}} & =\frac{\partial T_{I}}{\partial G_{I}} \times \frac{G_{I}}{T_{I}}=\frac{s^{2} T_{L}+s}{s^{2} T_{L}+\left(1+K_{e 1} T_{c 1}\right) s+K_{e 1}} \\
S_{G_{V}}^{T_{V}} & =\frac{\partial T_{V}}{\partial G_{V}} \times \frac{G_{V}}{T_{V}}=\frac{s^{2} T_{c}+s}{s^{2} T_{c}+\left(1+K_{e 2} T_{c 2}\right) s+K_{e 2}} \\
K_{e 1} & =\frac{V_{b} K_{P 1}}{I_{b} R_{L} T_{c 1}} \quad K_{e 2}=\frac{I_{b} R_{c} K_{P 2}}{V_{b} T_{c 2}} .
\end{aligned}
$$

The variations of the above sensitivities with frequency $f_{1}$ are shown in Fig. 13, which are obtained by replacing $s$ with $j 2 \pi f_{1}$ in (19) and (20) (see parameters in Table I). It can be seen that the sensitivities are negligible in the regions of interest. For instance, the input voltage estimator deals with rectified sinusoid, which has dc and second harmonic

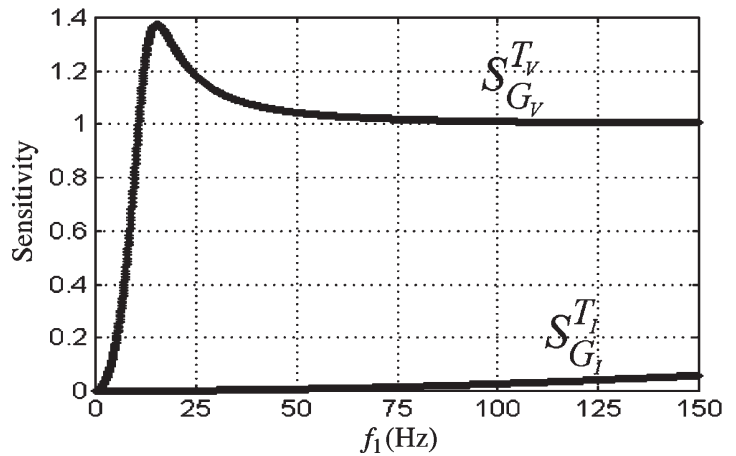

Fig. 13. Variations of sensitivities with frequency.
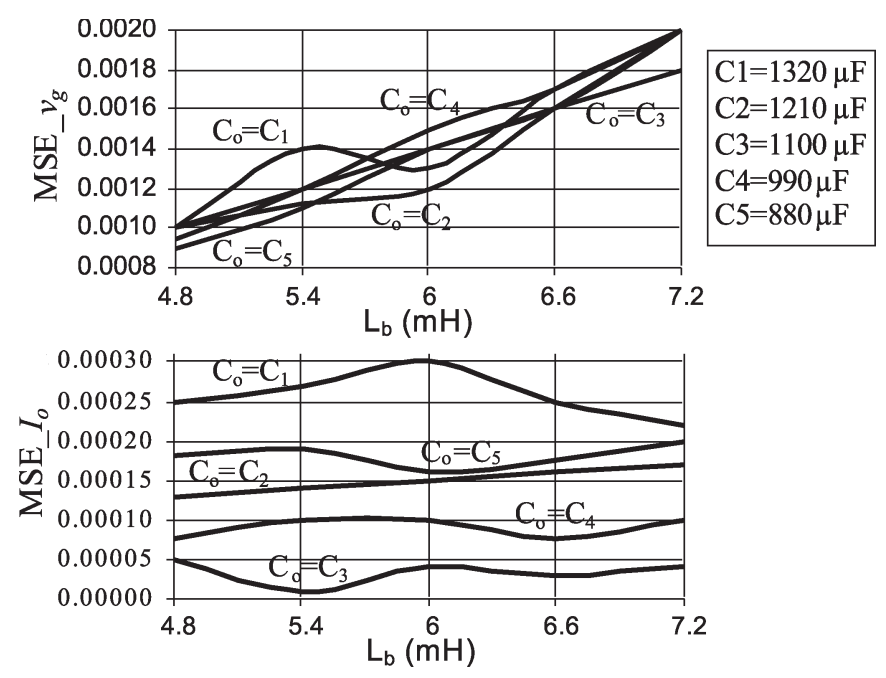

Fig. 14. Variations of the mean square errors (top) MSE_ $v_{g}$ and (bottom) MSE_ $I_{o}$ with respect to $L_{b}$ and $C_{o}$.

(100 Hz) components. The corresponding sensitivities, as seen in Fig. 13, are 0 and 0.06 , respectively. Similarly, the load current estimator deals with dc and has zero sensitivity in the region of interest.

The sensitivity analysis is also verified through simulation. Considering a $\pm 20 \%$ variation around the nominal values of $L_{b}(6 \mathrm{mH})$ and $C_{o}(1100 \mu \mathrm{F})$, the converter system (Fig. 3) is simulated in Matlab/Simulink platform. Fig. 14 shows the simulation results, which are obtained at rated input voltage and load current, where MSE_ $v_{g}$ and MSE_I $I_{o}$ are the normalized mean square errors in the input voltage and load current estimations defined as follows:

$$
\begin{aligned}
& \text { MSE_v } v_{g}=\frac{1}{T} \int_{0}^{T}\left[\left(v_{g(\mathrm{pu})}-\tilde{v}_{g(\mathrm{pu})}\right) / V_{g m(\mathrm{pu})}\right]^{2} d t \\
& \operatorname{MSE} \_I_{o}=\frac{1}{T} \int_{0}^{T}\left[\left(I_{o(\mathrm{pu})}-\tilde{I}_{o(\mathrm{pu})}\right) / I_{o(\mathrm{pu}) \mathrm{dc}}\right]^{2} d t .
\end{aligned}
$$

Here, $V_{g m(\mathrm{pu})}$ is the peak of the per-unit input voltage $v_{g(\mathrm{pu})}=$ $v_{g} / V_{b}$, and $I_{o(\mathrm{pu}) \mathrm{dc}}$ is the dc component of the per-unit rated load current $I_{o(\mathrm{pu})}=I_{o} / I_{b}$. It should be noted that $I_{o(\mathrm{pu})}$ contains a small low-frequency ripple (due to output voltage ripple). 


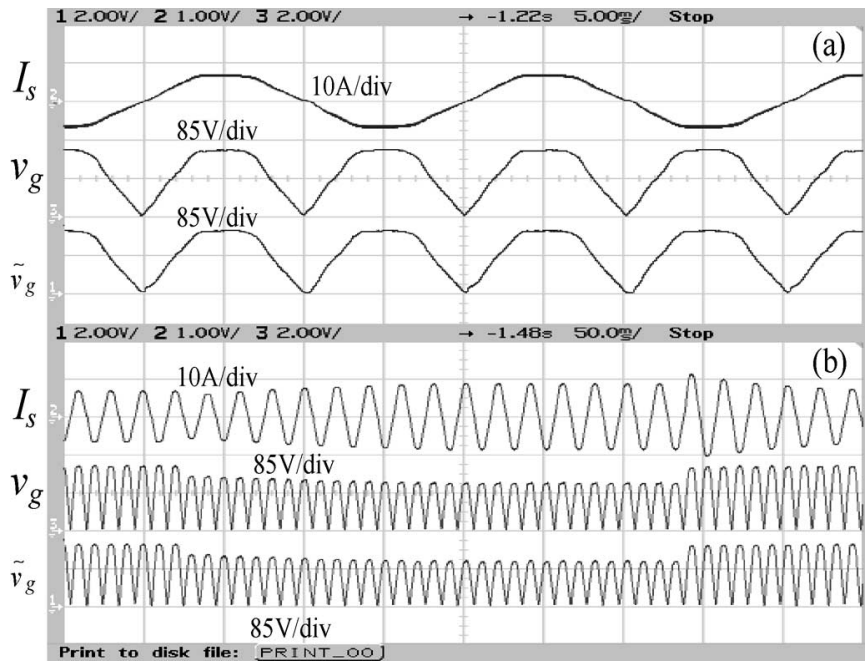

Fig. 15. Estimated input voltage. (a) Steady state. (b) Dynamic.

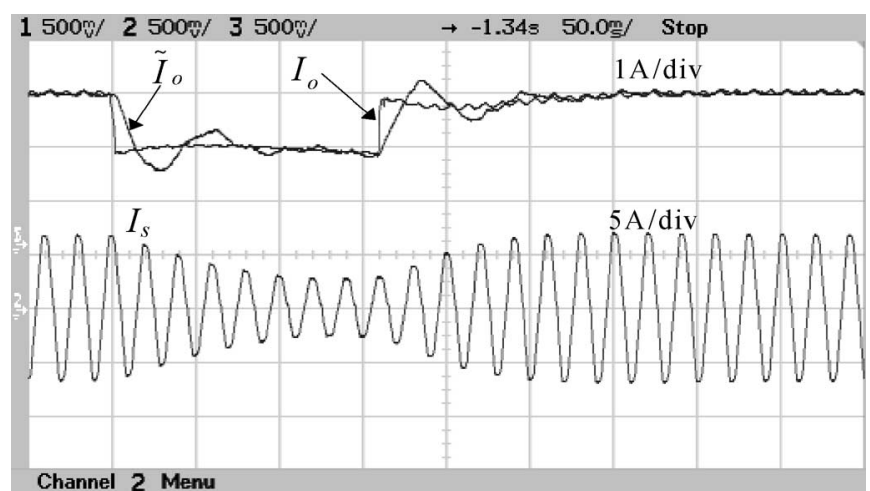

Fig. 16. Estimated load current.

Fig. 14 shows that the estimation errors under the rated operating condition are small. The estimation errors for few other operating conditions (load, input voltage, $R_{c}$ and $R_{L}$ ) are also found to be small through simulation.

\section{EXPERIMENTAL VERIFICATION}

The proposed feedforward control is verified on an experimental prototype. The block diagram and parameters of the prototype are shown in Fig. 3 and Table I, respectively. This section presents the various experimental results as obtained from the prototype.

\section{A. Estimated Input Voltage and Load Current}

The steady state and dynamic performance of the input voltage and load current estimators are shown in Figs. 15 and 16 , respectively. It can be seen that the estimated and the actual quantities closely follow each other.

\section{B. Steady State Input Voltage and Current}

The steady state input voltage and current waveforms for 600 and $300 \mathrm{~W}$ of output power are shown in Fig. 17. The corresponding input current THD are $3.7 \%$ and $4.3 \%$, respectively.

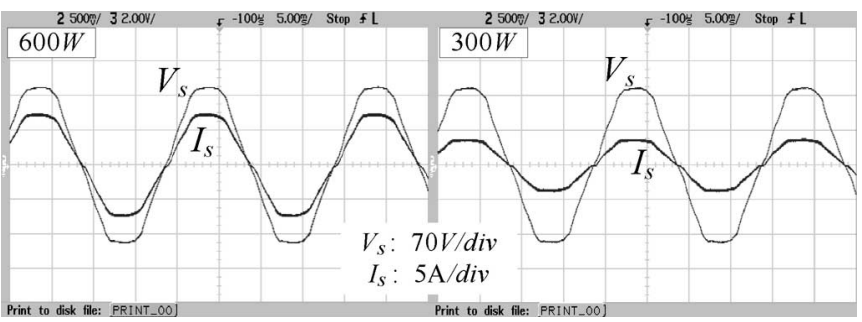

Fig. 17. Input voltages and input currents at $10-\mathrm{kHz}$ switching frequency.

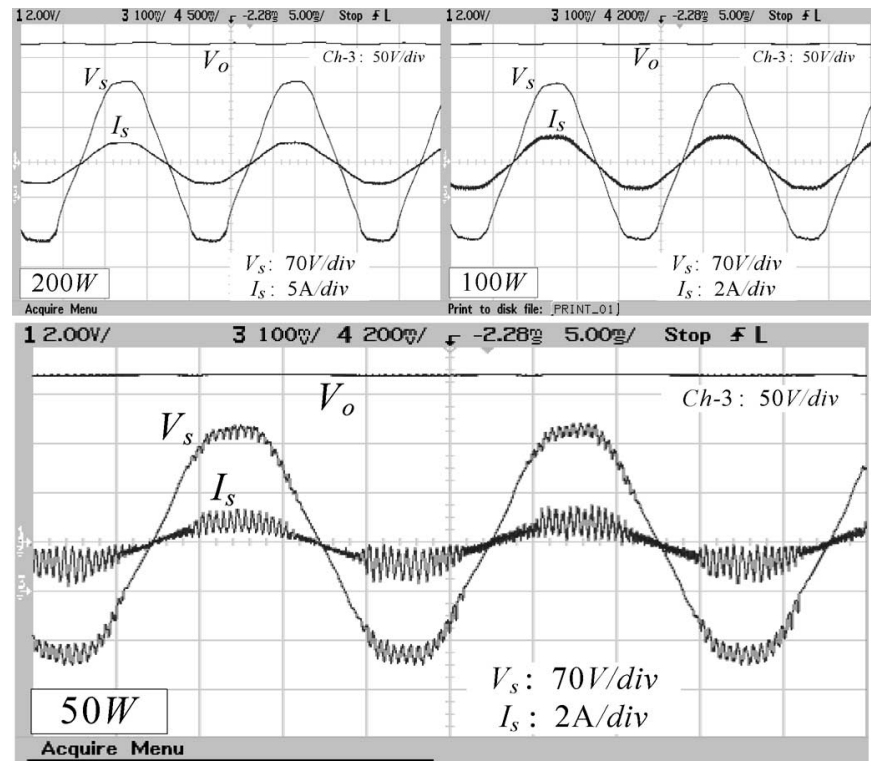

Fig. 18. Input voltages and currents at different loads at $10-\mathrm{kHz}$ switching frequency.

In order to verify the current loop instability (see Section IV-A), the converter output power is gradually reduced. It is found that the above instability appears for an output power less than $75 \mathrm{~W}$. Fig. 18 shows the output voltage, input voltage, and input current waveform at different loads, where the current loop instability is clearly seen at a $50-\mathrm{W}$ output.

One reason for the above instability is the delay $T_{d}$ associated with the digital implementation (see Section IV-A). In order to verify this, $T_{d}$ is reduced by increasing the switching frequency from 10 to $25 \mathrm{kHz}$. Further, instead of $6 \mathrm{mH}$, a 4-mH boost inductor is used. No oscillations are observed in the input current at $50 \mathrm{~W}$ load, as shown in Fig. 19. However, it is found that the instability reappears for output power around $45 \mathrm{~W}$.

\section{Dynamic Performance}

The system dynamic response is tested with three possible sources of disturbances, namely sudden changes in input voltage $v_{g}$, load current $I_{o}$, and reference voltage $V_{o}^{*}$. In order to make a one-to-one comparison, additional experimental results, as obtained with conventional control (without feedforward control) and with proposed feedforward control using input voltage and load current sensors (without using estimators), are presented. 


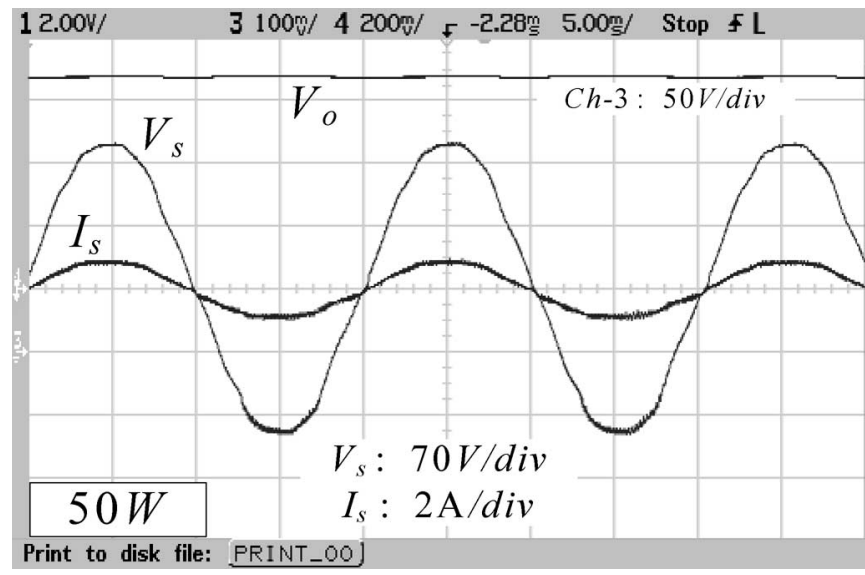

Fig. 19. Input voltage and current at $25-\mathrm{kHz}$ switching frequency.
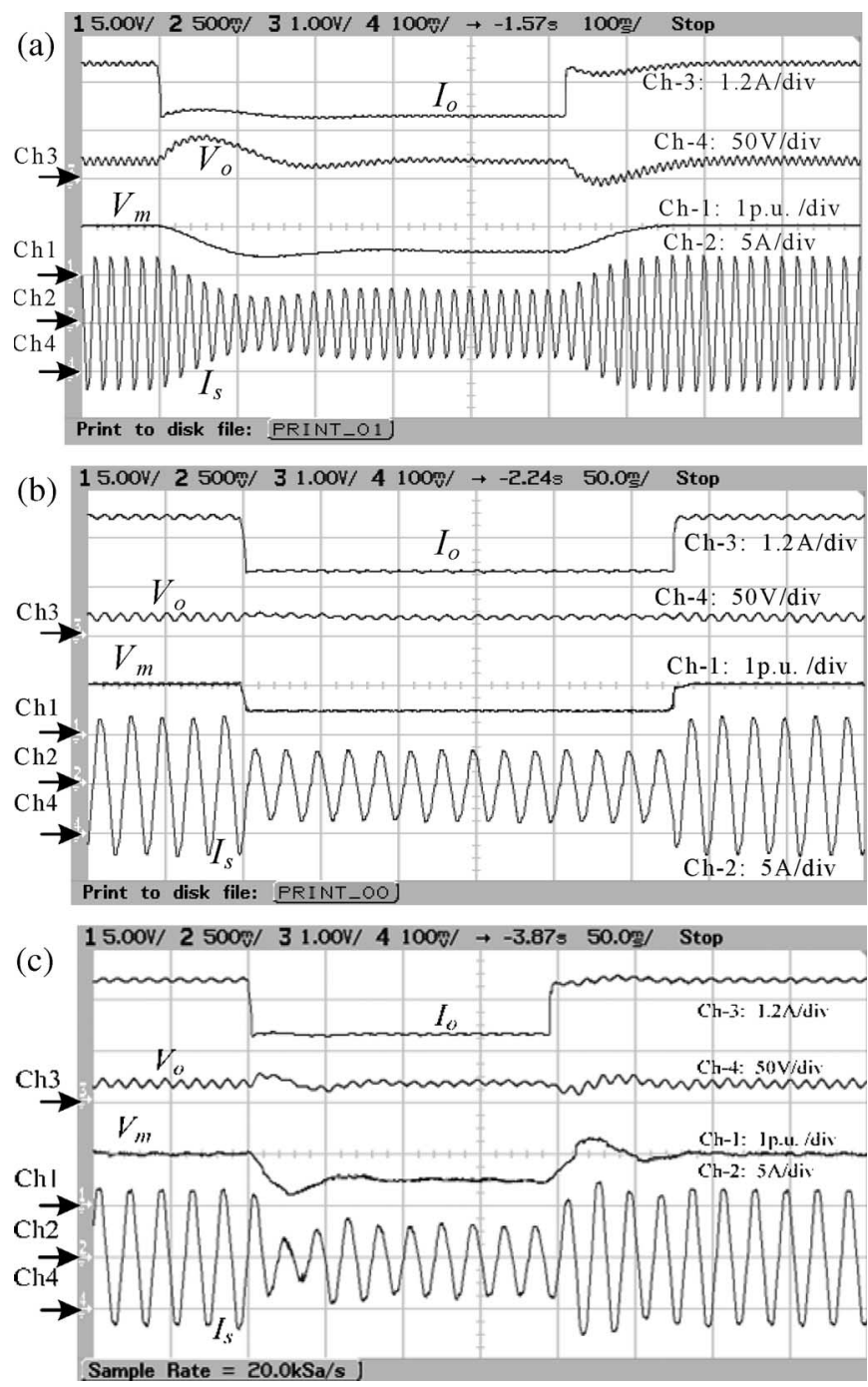

Fig. 20. Load dynamics. (a) Conventional control. (b) Feedforward control with input voltage and load current sensors. (c) Feedforward control with the proposed estimators.

The load dynamics corresponding to step changes in output power between 300 and $600 \mathrm{~W}$, under rated input voltage condition, are shown in Fig. 20.
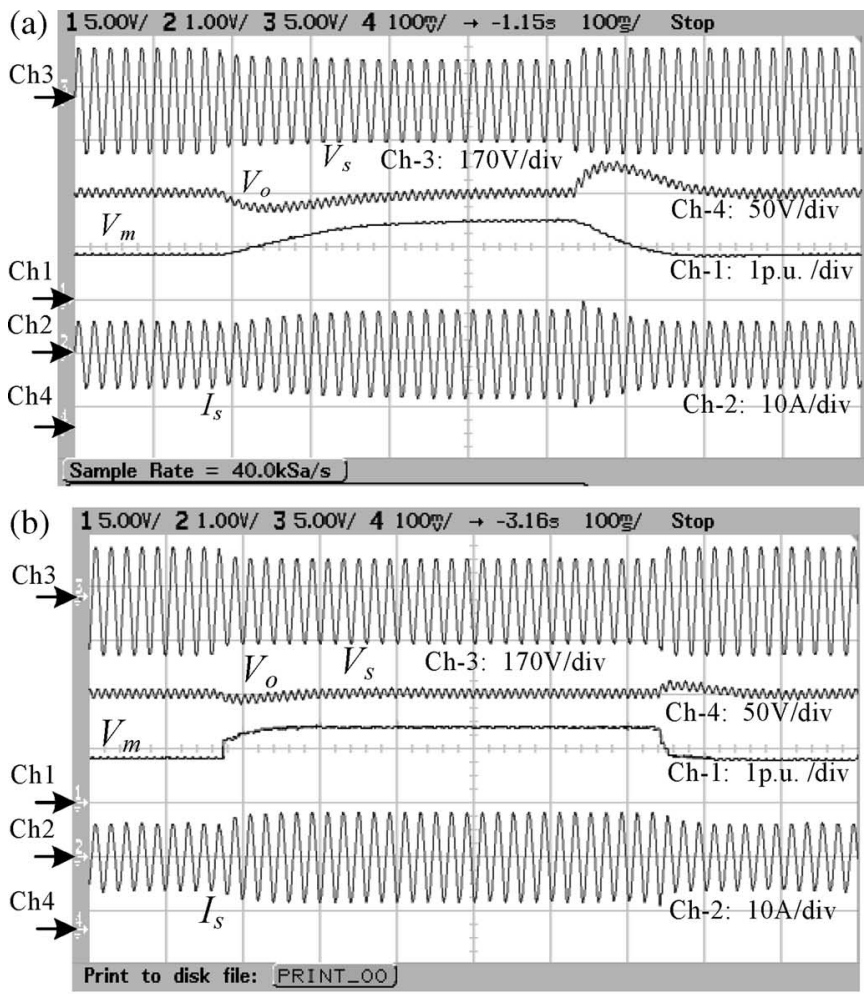

(c) $15.00 \mathrm{~V} / 21.00 \mathrm{~V} / 35.00 \mathrm{~V} / 4100 \mathrm{~m} / \rightarrow-6.68 \mathrm{~s} \quad 100 \mathrm{~m} / \mathrm{Stop}$

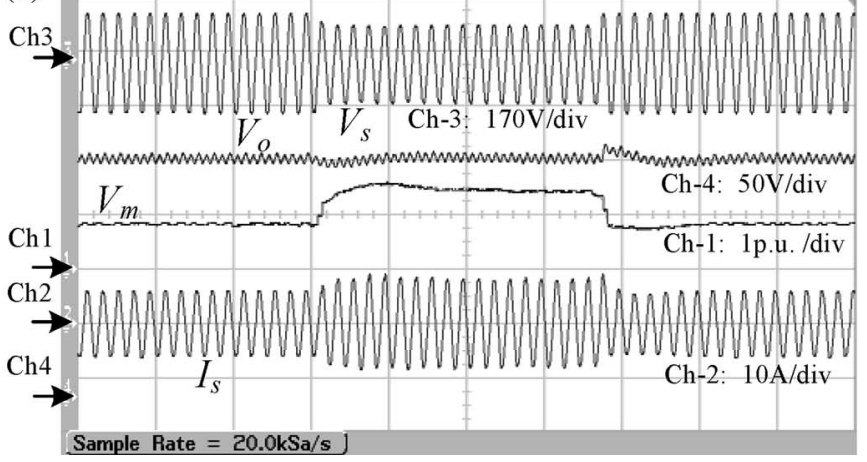

Fig. 21. Input voltage dynamics. (a) Conventional control. (b) Feedforward control with input voltage and load current sensors. (c) Feedforward control with the proposed estimators.

The system dynamics associated with step change in the input voltage between 90 and $120 \mathrm{~V}$ rms, under rated load, are shown in Fig. 21.

The dynamic responses of the system for a step change in the reference voltage between 215 and $250 \mathrm{~V}$, under rated input voltage and 50\% rated load, are shown in Fig. 22.

It is seen in Figs. 20-22 that the proposed feedforward control significantly improves the dynamic performances of the system over the conventional control method. The feedforward control, when implemented with input voltage and load current sensors, shows better dynamic performances over the results, obtained with corresponding estimators. This is due to the additional delay involved in the estimation process. Compared to Fig. 22(a), it is seen in Fig. 22(b) and (c) that in case of reference voltage dynamics, the proposed feedforward scheme decreases the transient time at the cost of slightly increased overshoot and undershoot in the output voltage. This is due to 

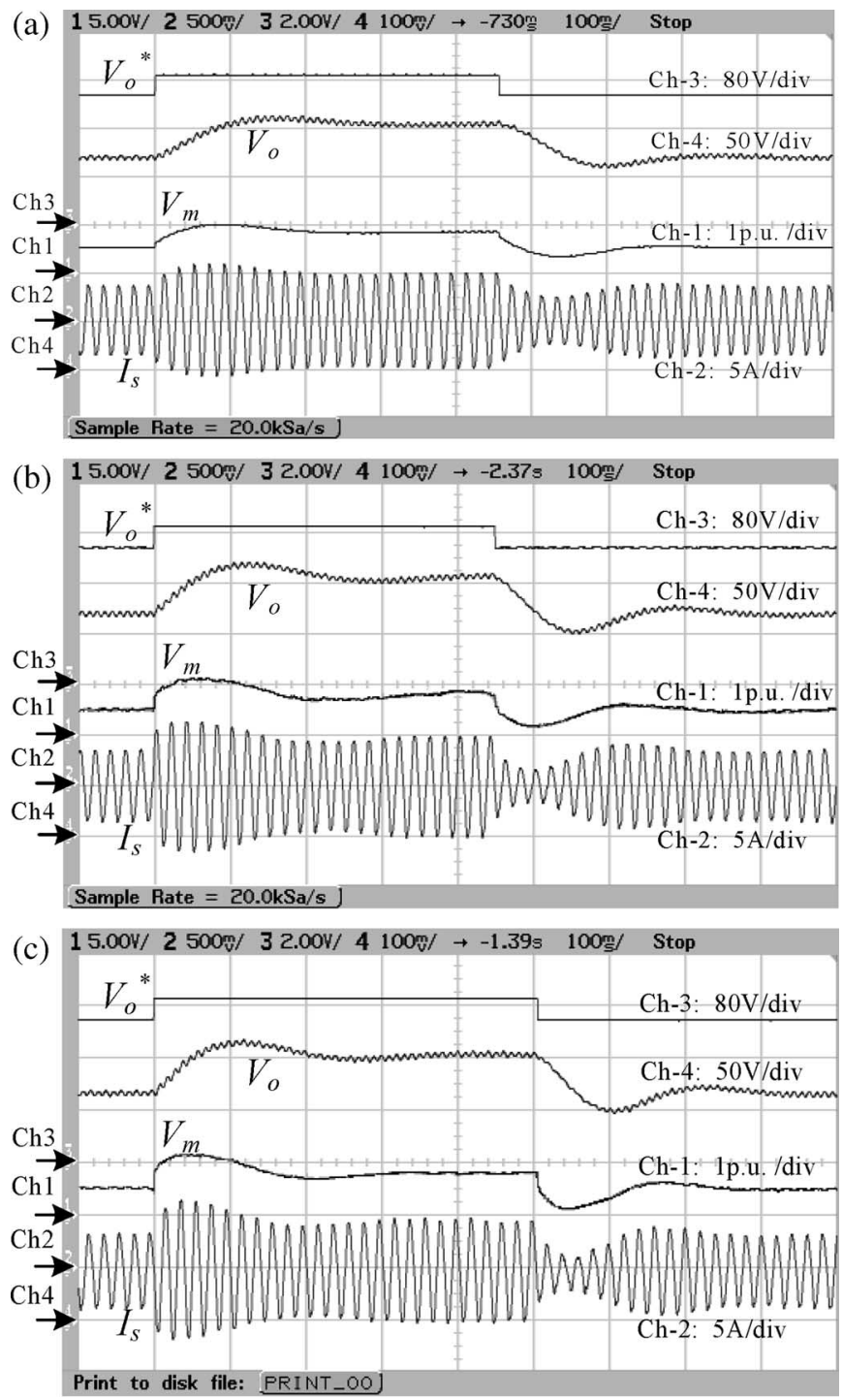

Fig. 22. Reference voltage dynamics. (a) Conventional control. (b) Feedforward control with input voltage and load current sensors. (c) Feedforward control with the proposed estimators.

the increase of the effective proportional gain of the voltage controller, as discussed in Section IV-B.

\section{CONCLUSION}

A digital feedforward control scheme, capable of compensating for line, load and reference voltage disturbances, has been presented for a single-phase boost rectifier, operating with indirect current control at a constant switching frequency. The converter system is designed for a low-bandwidth voltage loop. The dynamic response of the output voltage is improved by updating the input power reference quickly according to the load demand through a faster feedforward path. The required input voltage and load current information are obtained using two estimators.

The sensitivity analysis shows that the performances of the proposed estimators are less dependent on the real circuit parameter variations.
The small-signal analysis shows that the effective current loop is a second-order system due to the delay associated with digital implementation. The phase margin of the loop decreases with a decrease in the load current. This leads to instability in the current loop at light loads, which is investigated experimentally. It is shown that the region of instability can be restricted to be close to no load by increasing the switching frequency and reducing the boost inductor value.

Finally, an experimental validation of the proposed feedforward control was presented on a digitally controlled boost rectifier. The experimental results presented show improved output voltage dynamic response over conventional control (without feedforward). The dynamic response is comparable to that with the feedforward control using input voltage and load current sensors.

\section{REFERENCES}

[1] G. Moschopoulos and P. Jain, "Single-phase single-stage power-factorcorrected converter topologies," IEEE Trans. Ind. Electron., vol. 52, no. 1, pp. 23-35, Feb. 2005.

[2] W. Zhang, G. Feng, Y. F. Liu, and B. Wu, "New digital control method for power factor correction," IEEE Trans. Ind. Electron., vol. 53, no. 3, pp. 987-990, Jun. 2006.

[3] E. Figueres, J. M. Benavent, G. Garcera, and M. Pascual, "Robust control of power-factor-correction rectifiers with fast dynamic response," IEEE Trans. Ind. Electron., vol. 52, no. 1, pp. 66-76, Feb. 2005.

[4] Electromagnetic Compatibility Part 3: Limits-Section 2: Limits for Harmonic Currents Emissions (Equipment Input Current $<16$ A per Phase), IEC 1000-3-2, 1995.

[5] J. M. Benavent, E. Figueres, G. Garcera, C. Cerver, and M. Pascual, "Design and evaluation of a power factor correction rectifier with robust control and fast dynamic response," in Proc. IEEE PESC, Feb. 2004, vol. 3, pp. 2340-2345.

[6] G. Spiazzi, P. Mattavelli, and L. Rossetto, "Methods to improve dynamic response of power factor preregulators: An overview," in Proc. EPE, 1995, vol. 3, pp. 754-759.

[7] J. B. Williams, "Design of feedback loop in unity power factor AC to DC converter," in Proc. IEEE-PESC, Jun. 1989, vol. 2, pp. 959-967.

[8] S. Wall and R. Jackson, "Fast controller design for single-phase powerfactor correction systems," IEEE Trans. Ind. Electron., vol. 44, no. 5, pp. 654-660, Oct. 1997.

[9] M. M. Jovanovic, C. S. Leu, and F. C. Lee, "Zero-voltage-switched multiresonant converter for high-power, pulse-load applications," IEEE Trans. Ind. Electron., vol. 37, no. 6, pp. 544-555, Dec. 1990.

[10] A. Prodic, J. Chen, R. W. Erickson, and D. Maksimovic, "Digitally controlled low-harmonic rectifier having fast dynamic responses," in Proc. IEEE APEC, Mar. 2002, vol. 1, pp. 476-482.

[11] A. Prodic, J. Chen, D. Maksimovic, and R. W. Erickson, "Self-tuning digitally controlled low-harmonic rectifier having fast dynamic response," IEEE Trans. Power Electron., vol. 18, no. 1, pp. 420-428, Jan. 2003.

[12] A. Prodic, D. Maksimovic, and R. W. Erickson, "Dead-zone digital controllers for improved dynamic response of low harmonic rectifiers," IEEE Trans. Power Electron., vol. 21, no. 1, pp. 173-181, Jan. 2006.

[13] B. Arbetter and D. Maksimovic, "Feedforward pulse width modulators for switching power converters," IEEE Trans. Power Electron., vol. 12, no. 2, pp. 361-368, Mar. 1997.

[14] M. K. Kazimierczuk and A. Massarini, "Feedforward control of DC-DC PWM boost converter," IEEE Trans. Circuits Syst. I, Reg. Paper, vol. 44, no. 2, pp. 143-148, Feb. 1997.

[15] M. K. Kazimierczuk and L. A. Starman, "Dynamic performance of PWM DC-DC boost converter with input voltage feedforward control," IEEE Trans. Circuits Syst. I, Reg. Paper, vol. 46, no. 12, pp. 1473-1481, Dec. 1999.

[16] R. Redl and N. Sokal, "Near-optimum dynamic regulation of DC-DC converters using feed-forward of output current and input voltage with current-mode control," IEEE Trans. Power Electron., vol. PEL-1, no. 3, pp. 181-192, Jul. 1986.

[17] W. I. Tsai, Y. Y. Sun, and W. S. Shieh, "Modelling and control of single phase switching mode rectifiers with near-optimum dynamic regulation," in Proc. IEEE IECON, 1991, pp. 501-506. 
[18] M. T. Tsai and W. I. Tsai, "Analysis and design of three-phase AC-to-DC converters with high power factor and near-optimum feedforward," IEEE Trans. Ind. Electron., vol. 46, no. 3, pp. 535-543, Jun. 1999.

[19] S. B. Yaakov and I. Zeltser, "The dynamics of a PWM boost converter with resistive input," IEEE Trans. Power Electron., vol. 46, no. 3, pp. 613-619, Jun. 1999.

[20] Z. Lai and K. M. Smedley, "A family of continuous-conduction-mode power-factor-correction controllers based on the general pulse-width modulator," IEEE Trans. Power Electron., vol. 13, no. 3, pp. 501-510, May 1998.

[21] G. F. Franklin, J. D. Powell, and M. L. Workman, Digital Control of Dynamic Systems, 2nd ed. New York: Addison-Wesley, 1990.

[22] R. Ghosh and G. Narayanan, "A simple analog controller for singlephase half-bridge rectifier," IEEE Trans. Power Electron., vol. 22, no. 1, pp. 186-198, Jan. 2007.

[23] M. David, K. D. Gusseme, P. M. Alex, and J. A. Melkebeek, "Duty-ratio feedforward for digitally controlled boost PFC converters," IEEE Trans. Ind. Electron., vol. 52, no. 1, pp. 108-115, Feb. 2005.

[24] M. Chen and J. Sun, "Feedforward current control of boost single-phase PFC converters," in Proc. IEEE APEC, 2004, vol. 2, pp. 1187-1193.

[25] P. C. Todd, UC3854 Controlled, Power Factor Correction Circuit Design, Unitrode Corp., Merrimack, NH, Unitrode Appl. Note U-134, pp. 3-269-3-288, 1999.

[26] P. Mattavelli, G. Spiazzi, and P. Tenti, "Predictive digital control of power factor preregulators with input voltage estimation using disturbance observers," IEEE Trans. Power Electron., vol. 20, no. 1, pp. 140-147, Jan. 2005.

[27] D. M. Van de Sype, K. De Gusseme, A. P. Van den Bossche, and J. A. Melkebeek, "Small-signal Laplace-domain analysis of uniformlysampled pulse-width modulators," in Proc. IEEE PESC, 2004, pp. 4292-4298.

[28] I. J. Nagrath and M. Gopal, Control Systems Engineering. New Delhi, India: New Age International, 1996.

[29] J. Rajagopalan, F. C. Lee, and P. Nora, "A general technique for derivation of average current mode control laws for single-phase power-factorcorrection circuits without input voltage sensing," IEEE Trans. Power Electron., vol. 14, no. 4, pp. 663-672, Jul. 1999.

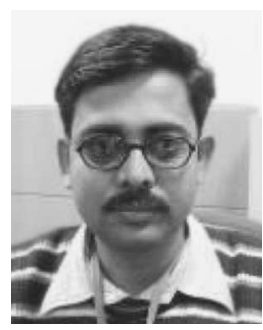

Rajesh Ghosh received the Diploma from Coochbehar Polytechnic, Coochbehar, India, in 1994, the B.E. degree from Jadavpur University, Kolkata, India, in 2000, and the M.Tech. degree from the Indian Institute of Technology, Kanpur, India, in 2002, all in electrical engineering. He is currently working toward the Ph.D. degree in the Department of Electrical Engineering, Indian Institute of Science, Bangalore, India.

Between 1994 and 2000, he was with the Substations Department of Calcutta Electric Supply Corporation Ltd. (CESC), involved in the maintenance, erection, and commissioning of LT/HT switchgears and power and distribution transformers. Between 2002 and 2003, he was with the GE Global Research Center (JFWTC), Bangalore, as an Electrical Engineer. His research interests are design, analysis, and control of switched-mode power converters and active power filters.

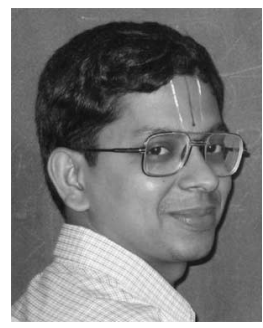

G. Narayanan (S'99-M'01) received the B.E. degree from Anna University, Chennai, India, in 1992 , the M.Tech. degree from the Indian Institute of Technology, Kharagpur, India, in 1994, and the Ph.D. degree from the Indian Institute of Science, Bangalore, India, in 2000.

$\mathrm{He}$ is currently an Assistant Professor in the Department of Electrical Engineering, Indian Institute of Science. His research interests include ac drives, pulsewidth modulation, multilevel inverters, and protection of power devices.

Dr. Narayanan received the Innovative Student Project Award for his Ph.D. work from the Indian National Academy of Engineering in 2000 and the Young Scientist Award from the Indian National Science Academy in 2003. 